\title{
Evolution Behavior of $\gamma-\mathrm{Al}_{3.5} \mathrm{FeSi}$ in $\mathrm{Mg}$ Melt and a Separation Method of Fe from Al-Si-Fe Alloys
}

\author{
Tong Gao ${ }^{1}$ Zeng-Qiang $\mathrm{Li}^{1} \cdot$ Yao-Xian Zhang ${ }^{1} \cdot$ Xiang-Fa Liu $^{1}$
}

Received: 18 May 2017/Revised: 18 June 2017/Published online: 5 July 2017

(c) The Chinese Society for Metals and Springer-Verlag GmbH Germany 2017

\begin{abstract}
The recycling of high Fe-content Al-Si alloys is a green industry. Eliminating the harmful effect of Fe, achieving the separation of $\mathrm{Al}$ and $\mathrm{Fe}$ is one of the key problems. Different from traditional methods for iron removal, a novel method using magnesium melt to separate $\mathrm{Al}$ and $\mathrm{Fe}$ is proposed. By introducing $\mathrm{Al}-14 \mathrm{Si}-5 \mathrm{Fe}$ alloy into $\mathrm{Mg}$ melt, it was found that the $\gamma-\mathrm{Al}_{3.5} \mathrm{FeSi}$ phase evolves to $\mathrm{Al}_{3} \mathrm{SiFe}_{3.5}$ and $\mathrm{Al}_{5} \mathrm{Fe}_{2}$ through the melting and solidification process. Compared with the primary Al-rich $\gamma-\mathrm{Al}_{3.5} \mathrm{FeSi}$ phase, the formation of $\mathrm{Fe}$-rich $\mathrm{Al}_{3} \mathrm{SiFe}_{3.5}$ is quite beneficial for the separation of $\mathrm{Al}$ and $\mathrm{Fe}$. $\mathrm{Mg}-\mathrm{Si}-\mathrm{Al}$ and $\mathrm{Mg}-\mathrm{Si}-\mathrm{Fe}$ alloys can be obtained at the top and bottom of the cooled ingot, respectively. The results in this study provide meaningful suggestions for recycling scrap $\mathrm{Al}-\mathrm{Si}-\mathrm{Fe}$ materials.
\end{abstract}

KEY WORDS: Al-Si-Fe; Mg melt; Fe-rich phase evolution; Separation

\section{Introduction}

Al materials have been widely used in industries due to their attractive properties, e.g., low density, low coefficient of thermal expansion and high strength-to-weight ratio [1]. With the decrease of primary $\mathrm{Al}$ resource in the world, the emphasis on recovering of scrap $\mathrm{Al}$ is increasing. Recycling of scrap Al materials has great potential and advantage in energy saving and environmental protection [2]. However, different from primary $\mathrm{Al}$, scrap $\mathrm{Al}$ ingots usually have non-negligible impurities, which make its recycling to be seriously restricted.

Available online at http://link.springer.com/journal/40195

Tong Gao

tgao@sdu.edu.cn

Xiang-Fa Liu

xfliu@sdu.edu.cn

1 Key Laboratory for Liquid-Solid Structural Evolution and Processing of Materials, Ministry of Education, Shandong University, Jinan 250061, China
Among amounts of $\mathrm{Al}$ scraps, $\mathrm{Al}-\mathrm{Si}-\mathrm{Fe}$ series are quite common since $\mathrm{Fe}$ is extremely easy to be introduced in $\mathrm{Al}$ alloys, especially for Al-Si alloys [3]. For instance, during the melting process, the use of unprotected ferrous tools and low-purity alloying materials will lead to the increase of $\mathrm{Fe}$ content in $\mathrm{Al}$ materials. Therefore, the $\mathrm{Fe}$ level in $\mathrm{Al}$ ingot constantly increases with each remelting cycle and finally reaches a quite high content, and sometimes it can be as high as $5 \mathrm{wt} \%$ [4]. As can be referred [5, 6], Fe is quite preferred to decrease the properties of $\mathrm{Al}-\mathrm{Si}$ alloys since the coarse Fe-rich particles prefer to cause cracks. Therefore, decreasing the detrimental effects of $\mathrm{Fe}$ is the key point for recycling $\mathrm{Al}-\mathrm{Si}-\mathrm{Fe}$ alloys.

The methods for reducing the negative impact of $\mathrm{Fe}$ in $\mathrm{Al}-\mathrm{Si}$ alloys have been investigated for decades [7]. One way is modifying the morphology of flake-like Fe-rich phase by overheating the melt or adding neutralized elements (Be, Cr, Mn, V, Co) etc. Gustafsson et al. [8] found that the addition of $\mathrm{Cr}$ in $\mathrm{A} 356$ alloy results in the transformation from $\beta-\mathrm{Al}_{5} \mathrm{FeSi}$ to $(\mathrm{Cr}, \mathrm{Fe})_{4} \mathrm{Si}_{4} \mathrm{Al}_{13}$. Liu et al. [9] achieved blocky $\alpha$-Fe phase transforming from $\beta$-Fe by overheating the scrap Fe-containing Al ingots. However, overheating the melt will increase the energy consumption, 
whereas addition of neutralized elements is easy to cause secondary pollution.

Another method is to aggregate and remove the Fe-rich phase through the methods of precipitation, centrifugation, gravity filtration, magnetic separation, etc. Matsubara et al. [10] reported that the Fe content in the center of $\mathrm{Al}-11 \mathrm{Si}-$ $2 \mathrm{Fe}$ ingot can decrease to $0.27 \%$ when centrifugal force was applied during the cooling procedure. El-Kaddah et al. [11] concluded that electromagnetism can be used to separate $\mathrm{Fe}$ in $\mathrm{Al}$ melt, since $\mathrm{Fe}$-rich phases move in opposite direction of the electromagnetic force. However, these methods also have non-negligible disadvantages, i.e., the methods are either less efficient or need complex ancillary equipment. In fact, the commonly used method in industries to recycle scrap $\mathrm{Al}-\mathrm{Si}-\mathrm{Fe}$ alloys currently is using primary aluminum for dilution. As a result, only $20-30 \%$ scrap Al can be used for each melting work.

In this paper, an $\mathrm{Al}-14 \mathrm{Si}-5 \mathrm{Fe}$ ingot was introduced into $\mathrm{Mg}$ melt. The evolution of Fe-rich particles was found during the melting and solidification procedures. As a result, the separation of $\mathrm{Al}$ and $\mathrm{Fe}$ was achieved to some extent. A high Fe-content $\mathrm{Mg}-\mathrm{Si}-\mathrm{Fe}$ alloy was obtained at the bottom of the cooled ingots, whereas $\mathrm{Mg}-\mathrm{Si}-\mathrm{Al}$ alloys formed at the top. Related mechanisms of phase evolution were discussed.

\section{Experimental}

The raw material contains commercial pure $\mathrm{Mg}$ ingots (99.8\%, all compositions quoted in this paper are in $\mathrm{wt} \%$ unless otherwise stated) and $\mathrm{Al}-14 \mathrm{Si}-5 \mathrm{Fe}$ ingot (Provided by Shandong Al\&Mg Melt Technology Co. Ltd).

First, $\mathrm{Mg}$ ingots were melted under the protection of $1 \%$ RJ-2 flux (40-50\% $\mathrm{MgCl}_{2}, 35-45 \% \mathrm{KCl}, 5-8 \% \mathrm{BaCl}_{2}$, $5-8 \% \mathrm{CaF}_{2}, 5-8 \% \mathrm{NaCl}+\mathrm{CaCl}_{2}$ ) in a ceramic crucible using a resistance furnace heating to $760{ }^{\circ} \mathrm{C}$. Then, Al$14 \mathrm{Si}-5 \mathrm{Fe}$ alloy was added in the melt with the adding amount of $10 \%$. After that, the melts were held for $30 \mathrm{~min}$ or $3 \mathrm{~min}$, during which regular stirs were applied. Finally, the crucible was transferred in air or cooled in the furnace to room temperature.

The specimens for metallography were cut from the bottom center of the cooled ingots, then mechanically grounded and polished by using $\mathrm{MgO}$ turbid liquid in standard routines. 5 vol.\% acetic acid water solution was used to extract Fe-rich particles from the alloys for observing the three-dimensional morphology directly, using the method in Ref. [12].

The microstructure observations were carried out by a Leica DM2700 optical microscope (OM) and field emission scanning electron microscopy (FESEM), i.e., a SU-70 scanning electron microscope operated at $15 \mathrm{kV}$ and linked with an energy dispersive X-ray spectrometry (EDS) attachment. The phase identification of the samples was detected by X-ray diffraction (XRD) by a Rigaku D/max$\mathrm{rB}$ diffractometer using $\mathrm{Cu} K_{\alpha}$ radiation at $40 \mathrm{kV}$ and $100 \mathrm{~mA}$.

An Inductively Coupled Plasma-Atomic Emission Spectrometer PE8000 machine was used to analyze the element concentrations of the samples. At least, four values were collected for each sample and an average value was reported in this paper.

\section{Results and Discussion}

Figure 1a shows microstructure of the Al-14Si-5Fe alloy. It was found that the main Fe-rich intermetallics exhibit block-like, with the average size of $\sim 38 \mu \mathrm{m}$. XRD pattern of this alloy is displayed in Fig. 1b in which, except for the $\mathrm{Al}$ matrix and $\mathrm{Si}, \gamma-\mathrm{Al}_{3.5} \mathrm{FeSi}$ phase was identified. The fractograph of the three-dimensional morphology of the $\gamma$ $\mathrm{Al}_{3.5} \mathrm{FeSi}$ crystal is presented in Fig. 1c. It can be seen that the $\gamma-\mathrm{Al}_{3.5} \mathrm{FeSi}$ crystal performs as polyhedron, covered by smooth crystallographic faces. EDS result (Fig. 1d) confirms that the phase is $\gamma-\mathrm{Al}_{3.5} \mathrm{FeSi}$ with the composition of as high as 63.27 at.\% $\mathrm{Al}$.

By introducing the $\mathrm{Al}-14 \mathrm{Si}-5 \mathrm{Fe}$ ingot into the crucible filled with $\mathrm{Mg}$ melt (Fig. 2a) then holding for $30 \mathrm{~min}$ and cooling in the air, a deposition layer was obtained at the bottom of the cooled ingot (Fig. 2b). FESEM image indicates that amounts of Fe-rich particles locate at the bottom, whereas only $\mathrm{Mg}$ matrix and $\beta-\mathrm{Al}_{12} \mathrm{Mg}_{17}$ on the top, as shown in Fig. 2c. The size and shape of the Fe-rich particles are shown in Fig. 3. It can be found that the particles exhibit elliptical, with the average size of $\sim 7 \mu \mathrm{m}$. It is quite interesting to notice that most of the particles exhibit core-shell shape and the volume ratio between the core and shell varies with different particles.

Figure 4 shows the mappings of several core-shell particles by conducting area scanning analysis. From the elements distribution, it was found that compared with the cores, the shells have a higher content of Al. EDS spectrums as well as the compositions of the core-shell particles are shown in Fig. 5. Based on the content of $\mathrm{Al}$, $\mathrm{Si}$ and $\mathrm{Fe}$ in the particles, it was deduced that the core is a ternary phase which can be expressed by the chemical formula $\mathrm{Al}_{3} \mathrm{SiFe}_{3.5}$, whereas the shell is binary $\mathrm{Al}_{5} \mathrm{Fe}_{2}$ phase.

As mentioned earlier and shown in Fig. 3, since the shell covers the core and different particles have various size of shell, it is reasonable to deduce that the outer $\mathrm{Al}_{5} \mathrm{Fe}_{2}$ phase is evolved from the inner $\mathrm{Al}_{3} \mathrm{SiFe}_{3.5}$ phase. The reason why not all of the cores were swallowed by the shells is from the cooling condition. From the experiments mentioned above, 

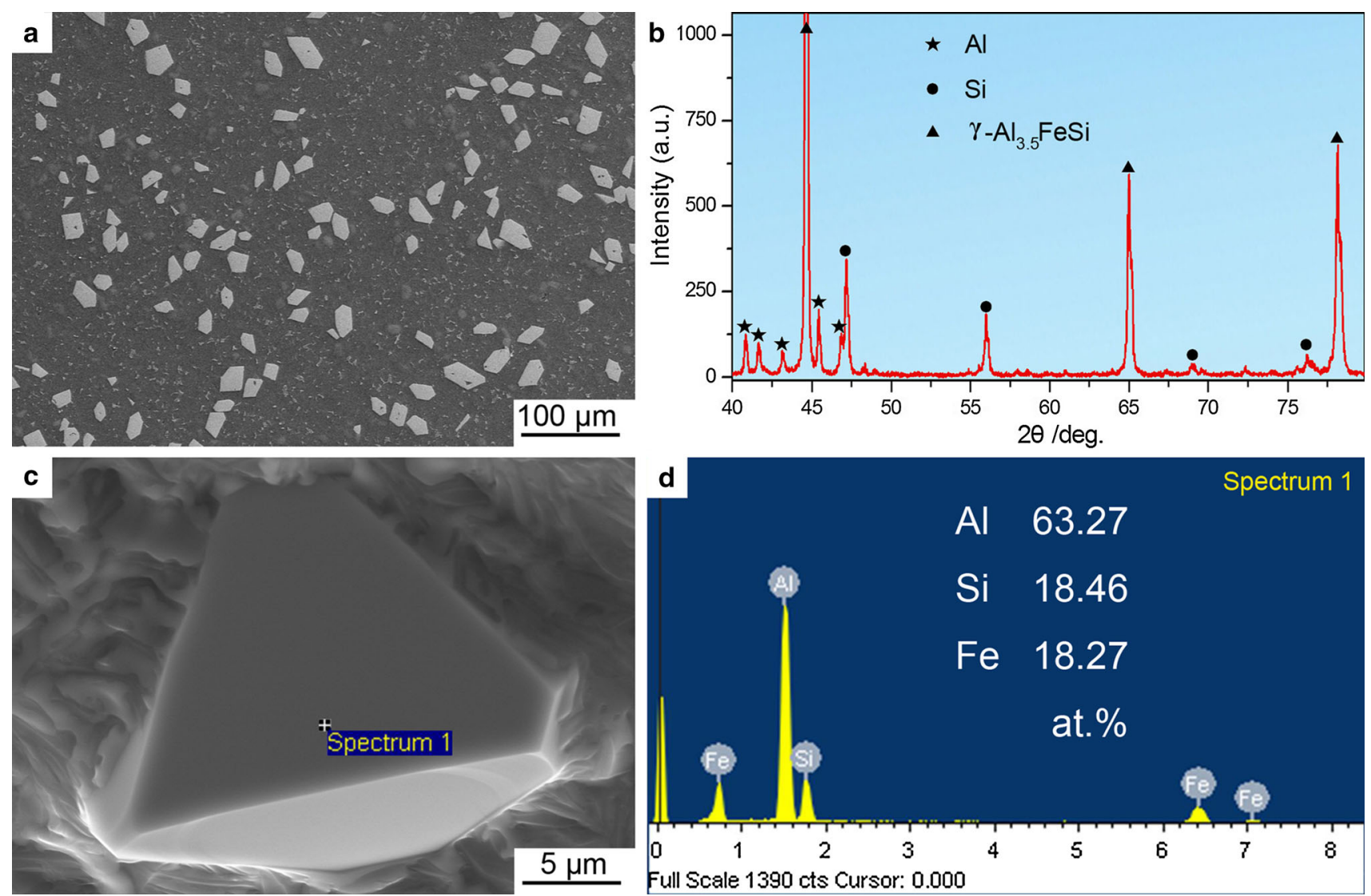

Fig. 1 a, b Microstructure and XRD of the Al-14Si-5Fe alloy; c, d 3D morphology and EDS of the $\gamma-\mathrm{Al}_{3.5} \mathrm{FeSi}$ particle
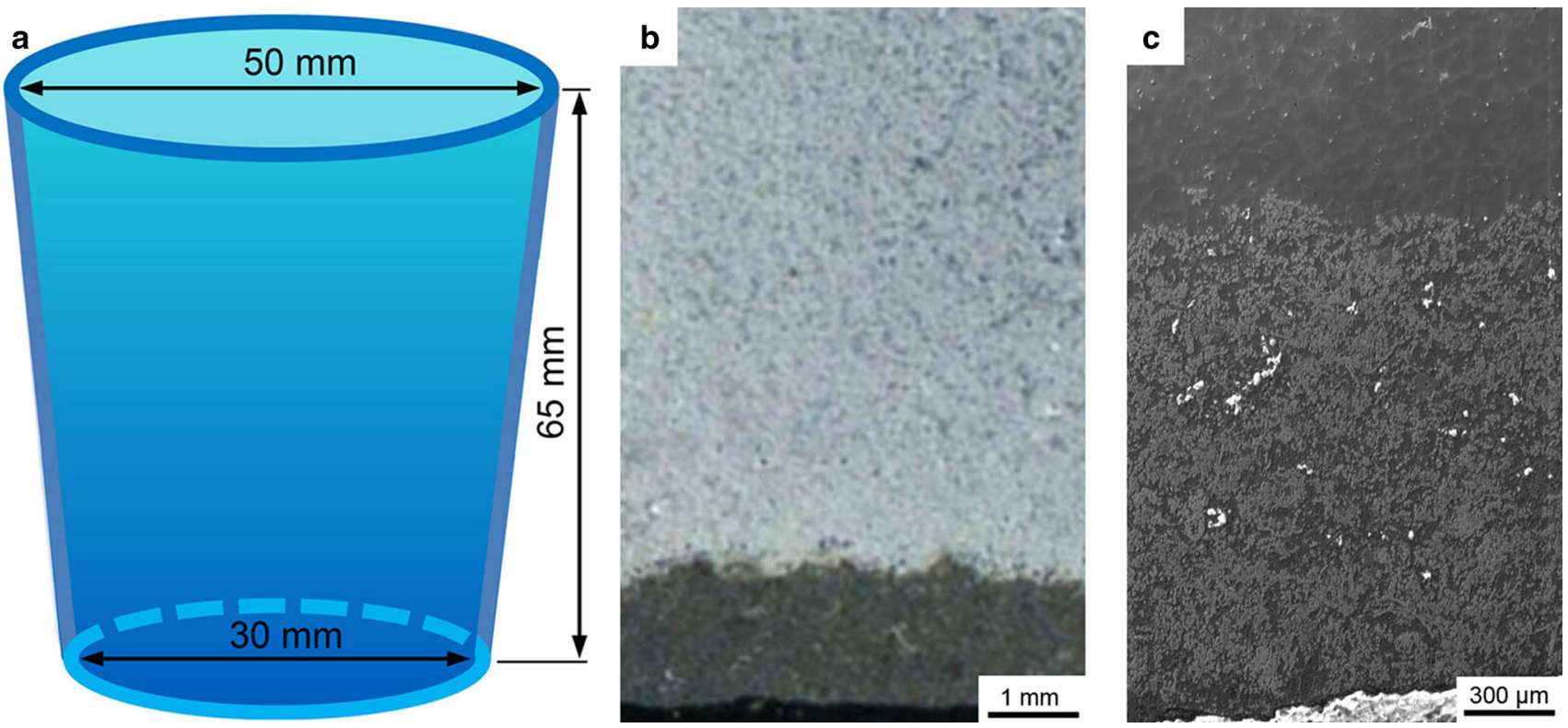

Fig. 2 a Size of the crucible; b, $\mathbf{c ~ O M}$ and FESEM images of bottom of the cooled ingot, showing the deposition layers

the crucible was cooled in air which has a relatively high solidification rate. It is regarded that the $\mathrm{Al}_{3} \mathrm{SiFe}_{3.5}$ is a meta-stable phase which only exists at a relatively high temperature in the $\mathrm{Mg}$ melt. Therefore, during the cooling process, the pre-precipitated $\mathrm{Al}_{3} \mathrm{SiFe}_{3.5}$ particles prefer to evolve to $\mathrm{Al}_{5} \mathrm{Fe}_{2}$. Due to the limitation of cooling time, the 

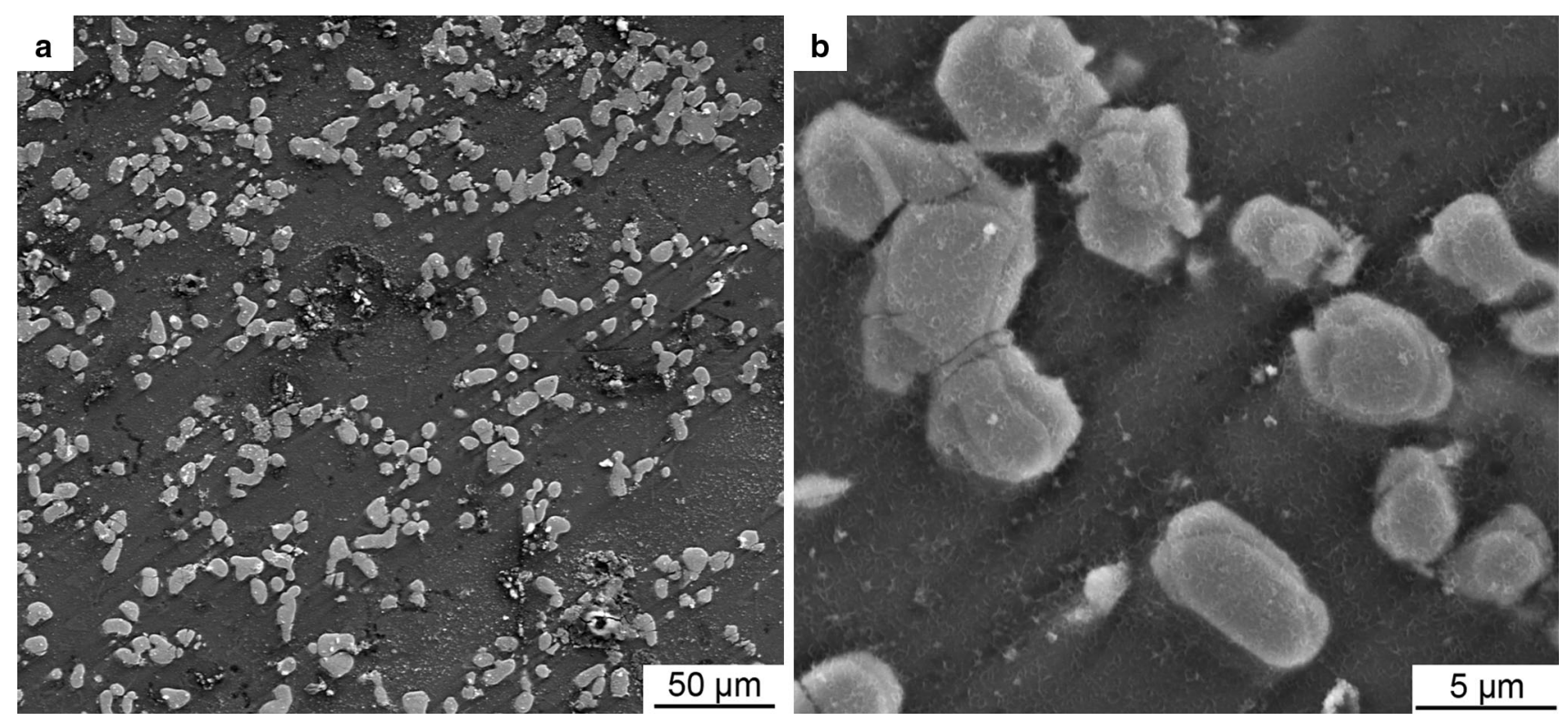

Fig. 3 a Microstructure of the deposition layer; b The core-shell Fe-rich particles
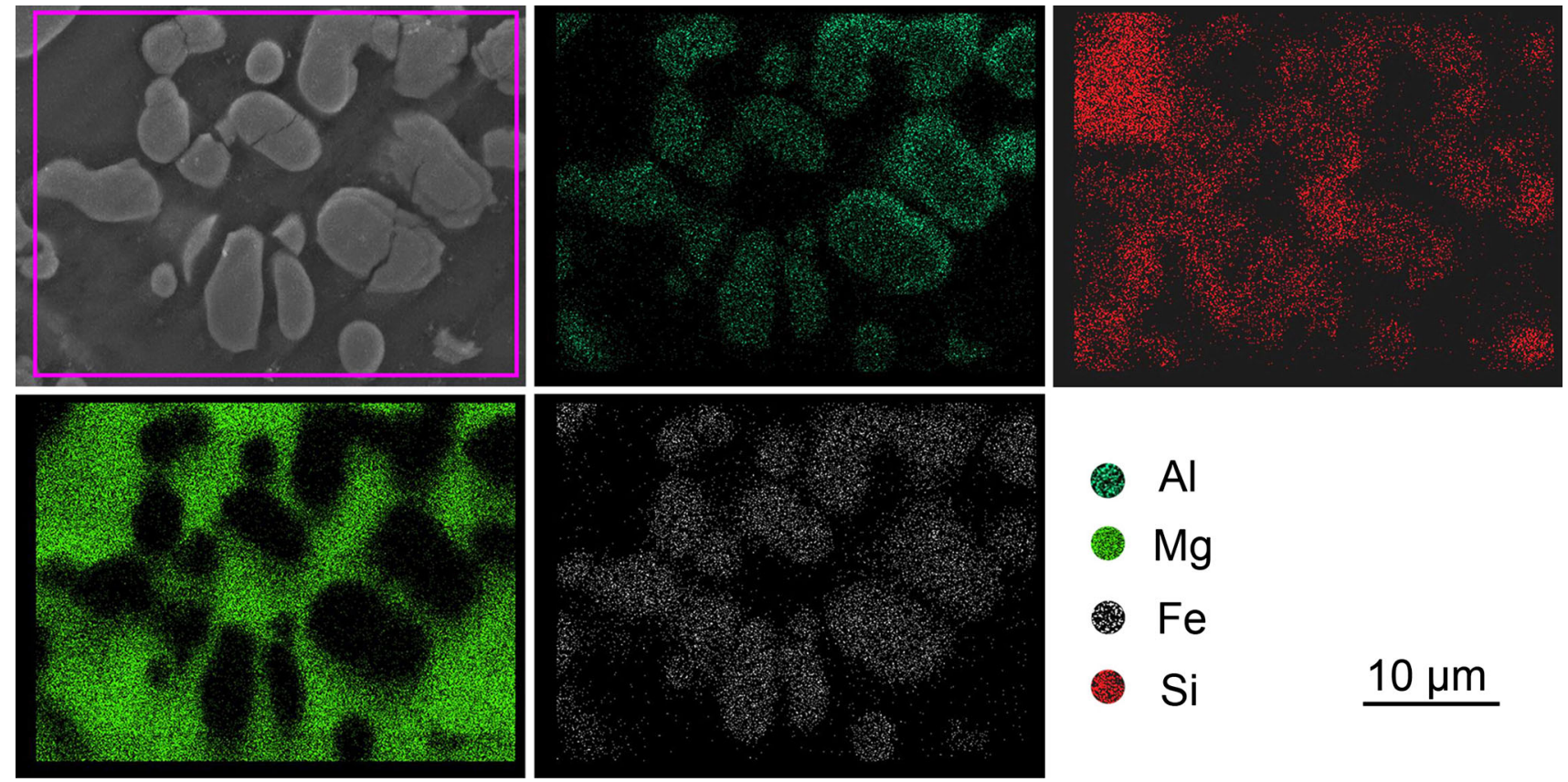

Fig. 4 Scanning maps of the core-shell Fe-rich particles

evolution procedure cannot complete totally, thus resulting in the core-shell-shaped particles.

To confirm this hypothesis, another experiment was conducted. All the experimental parameters are the same to the previous except that the melt was cooled in the resistance furnace. Under this condition, the cooling rate is quite low and the melt can be regarded as solidified through an equilibrium process. The obtained Fe-rich particles are shown in Fig. 6a, and no core-shell-shaped particles were found. EDS result indicates that all the blocky particles are
$\mathrm{Al}_{5} \mathrm{Fe}_{2}$ (Fig. 6b). Therefore, this result positively supports the above hypothesis.

Another experiment was then conducted, aiming at understanding what happened on the $\gamma-\mathrm{Al}_{3.5} \mathrm{FeSi}$ particles (Fig. 1a) after the $\mathrm{Al}-14 \mathrm{Si}-5 \mathrm{Fe}$ ingot was introduced into $\mathrm{Mg}$ melt. Different from the holding time of $30 \mathrm{~min}$ in the above two experiments, the melt was only held for $3 \mathrm{~min}$. The cooling condition was changed with a quite faster rate, i.e., the bottom of the melt was poured into a copper mold to remain the intermediate state of the phase evolution 


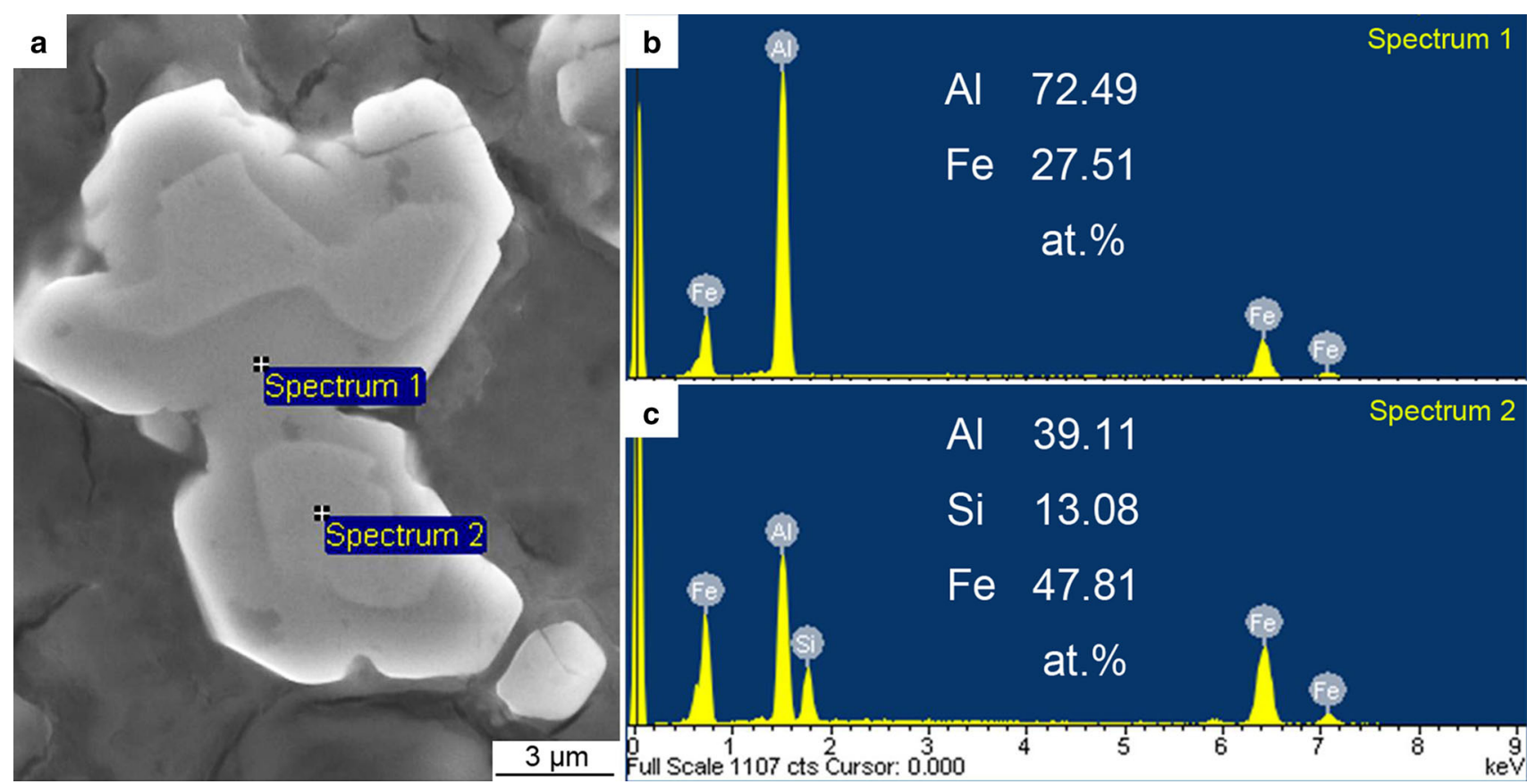

Fig. 5 The core-shell Fe-rich particles a and corresponding EDS results of the shell $\mathbf{b}$, core $\mathbf{c}$
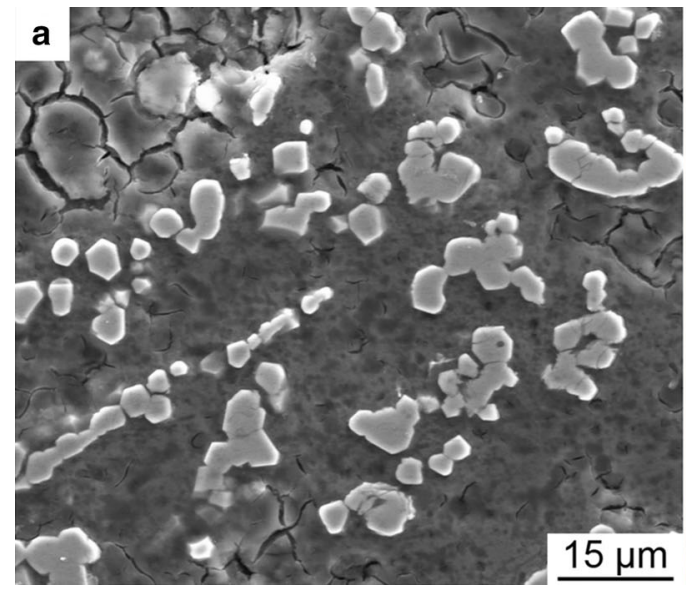

\section{b}

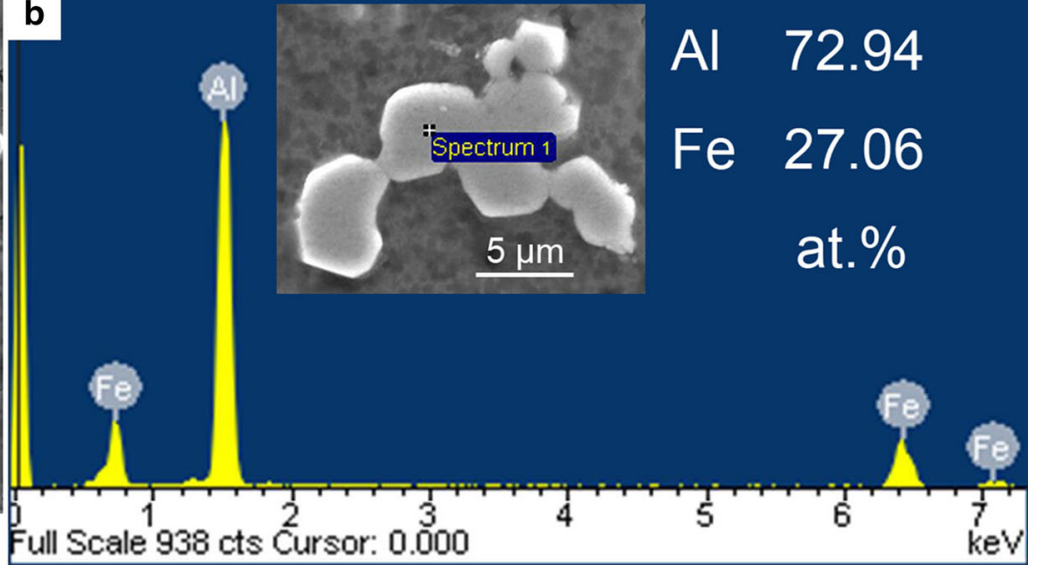

Fig. 6 Microstructure a and EDS $\mathbf{b}$ of the Fe-rich particles in the solidified ingot with an extremely low cooling rate

procedure. The microstructure is shown in Fig. 7a, in which the particle clusters also keep the initial outline, similar to that of blocky $\gamma-\mathrm{Al}_{3.5} \mathrm{FeSi}$ particles (Fig. 1a). However, obvious decomposition phenomenon was observed on these particles. Figure $7 \mathrm{~b}$ shows three-dimensional morphology of the particles. It was found that the particles are polyporus, exhibiting coralline. EDS result (Fig. 7c) indicates that the coralline particles are the $\mathrm{Al}_{3}$ $\mathrm{SiFe}_{3.5}$ phase above mentioned. Therefore, based on the experimental results, it can be deduced that after Al-14Si$5 \mathrm{Fe}$ alloy was added into the $\mathrm{Mg}$ melt, phase structure evolution $\left(\gamma-\mathrm{Al}_{3.5} \mathrm{FeSi} \rightarrow \mathrm{Al}_{3} \mathrm{SiFe}_{3.5}\right)$ and morphology evolution (big blocky $\rightarrow$ coralline $\rightarrow$ small ellipsoid) occur during the holding process, as shown in Fig. $7 \mathrm{~d}$
(Stage I). Then, in the following cooling process (Stage II, Fig. 7d), $\mathrm{Al}_{5} \mathrm{Fe}_{2}$ phase occurs and the small ellipsoid $\mathrm{Al}_{3}$ $\mathrm{SiFe}_{3.5}$ particles evolve to core-shell shape as mentioned above.

As discussed at the beginning, finding a proper method for recycling high $\mathrm{Fe}$-content $\mathrm{Al}-\mathrm{Si}-\mathrm{Fe}$ alloy is of great significance. By using the method in this paper, Al-rich $\mathrm{Al}_{3.5} \mathrm{SiFe}$ phase evolves to Fe-rich $\mathrm{Al}_{3} \mathrm{SiFe}_{3.5}$. Through this process, amounts of $\mathrm{Al}$ atoms are released into the $\mathrm{Mg}$ melt and Fe-rich particles are collected at the bottom. Table 1 shows composition of the cooled samples in the top (T\#) and bottom (B\#). Since $10 \mathrm{wt} \% \mathrm{Al}-14 \mathrm{Si}-5 \mathrm{Fe}$ alloy was added into $\mathrm{Mg}$ melt, the nominal Fe content is $0.5 \%$. From Table 1, it can be found that at the top of the ingot which 

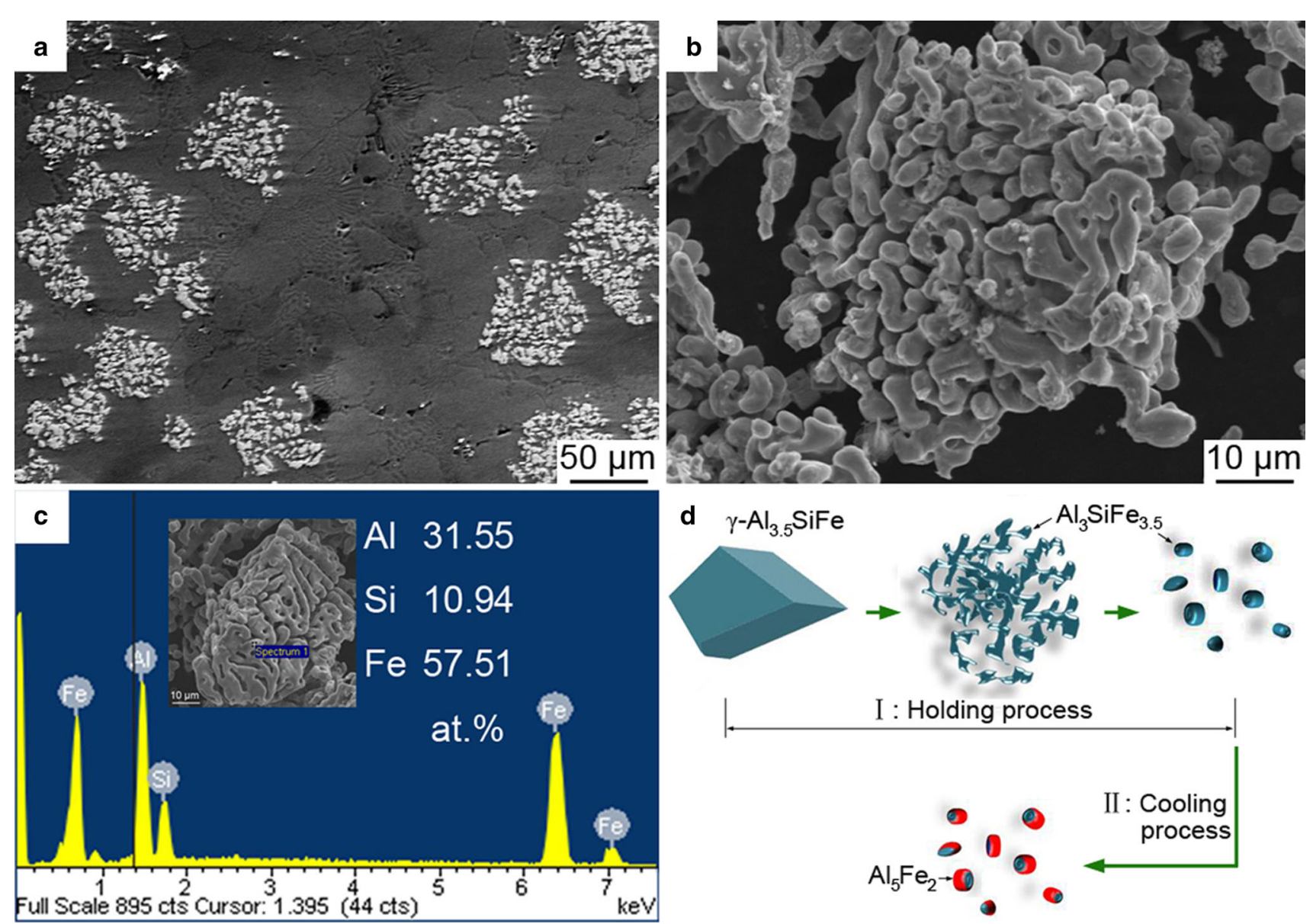

Fig. 7 a Microstructure of the Fe-rich particles in the intermediate evolution state; b, c 3-D morphology and EDS result of the Fe-rich particles; d Schematic diagram of the evolution of Fe-rich phase during the holding and cooling process

Table 1 Chemical composition of the alloys in the top and bottom of the solidified ingots

\begin{tabular}{llllll}
\hline Sample & \multicolumn{5}{l}{ Average element contents } \\
\cline { 2 - 6 } & $\mathrm{Al}$ & \multicolumn{1}{c}{$\mathrm{Si}$} & $\mathrm{Fe}$ & $\mathrm{Mg}$ & Impurities \\
\hline $\mathrm{B \#}$ & 1.05 & $>1.60$ & 5.38 & 91.4 & Balance \\
$\mathrm{T \#}$ & 8.35 & 1.03 & 0.0378 & 90.5 & Balance \\
\hline
\end{tabular}

T\# and B\# are the samples in the top and bottom of the cooled ingot, respectively

can be named as $\mathrm{Mg}-\mathrm{Si}-\mathrm{Al}$, the alloy has a quite low $\mathrm{Fe}$ content, i.e., $0.0378 \%$, whereas at the bottom, $\mathrm{Mg}-\mathrm{Si}-\mathrm{Fe}$ contains up to $5.38 \mathrm{wt} \% \mathrm{Fe}$. Besides, the heights of $\mathrm{Mg}-\mathrm{Si}-$ $\mathrm{Fe}$ and $\mathrm{Mg}-\mathrm{Si}-\mathrm{Al}$ layers in this ingot were detected to be $1.7 \mathrm{~mm}$ and $55.3 \mathrm{~mm}$, respectively. Therefore, the volume of bottom alloy in the whole sample can be calculated to be $\sim 1.25 \%$, indicating the effective separation efficiency of $\mathrm{Al}$ and $\mathrm{Fe}$ by this method.

Compared with the methods above mentioned [8-11], the method proposed in this paper for separating $\mathrm{Al}$ and $\mathrm{Fe}$ is supposed to have advantages to some extent. For instance, this method neither needs complex ancillary equipment nor causes excess energy consuming. However, it is still necessary to mention that from the viewpoint of recycling scrap $\mathrm{Al}-\mathrm{Si}-\mathrm{Fe}$ materials, $\mathrm{Al}_{3} \mathrm{SiFe}_{3.5}$ particles are more preferred than $\mathrm{Al}_{5} \mathrm{Fe}_{2}$, since $\mathrm{Al}_{3} \mathrm{SiFe}_{3.5}$ phase has a higher $\mathrm{Fe}$ content and lower $\mathrm{Al}$ content. Therefore, by applying a proper melting and cooling technology, e.g., creating faster cooling condition, making Fe-rich phase evolves to a Fe-rich one is of great significance. There is no doubt that further studies are still needed.

\section{Conclusions}

By introducing $\mathrm{Al}-14 \mathrm{Si}-5 \mathrm{Fe}$ alloy into $\mathrm{Mg}$ melt, the $\gamma$ $\mathrm{Al}_{3.5} \mathrm{FeSi}$ phase was found to evolve to $\mathrm{Al}_{3} \mathrm{SiFe}_{3.5}$ during the holding procedure. Correspondingly, the block particles decompose into coralline and finally to small ellipsoids. During the cooling procedure, the $\mathrm{Al}_{3} \mathrm{SiFe}_{3.5}$ phase evolves to $\mathrm{Al}_{5} \mathrm{Fe}_{2}$, leading to the formation of core-shell-shaped particles. After cooling, $\mathrm{Mg}-\mathrm{Si}-\mathrm{Fe}$ alloy and $\mathrm{Mg}-\mathrm{Si}-\mathrm{Al}$ 
alloys can be obtained at the bottom and top of the melt, respectively. It is regarded that the experiment in this paper enlightens a novel method to recycle $\mathrm{Al}-\mathrm{Si}-\mathrm{Fe}$ alloys in industries.

Acknowledgements This research was financially supported by the National Natural Science Foundation of China (No. 51601106), the Fundamental Research Funds of Shandong University, and China Postdoctoral Science Foundation (No. 2016M600536).

\section{References}

[1] X.Y. Yan, S.C. Sun, Z.Y. Jiang, Acta Metall. Sin. (Engl. Lett.) 15, 531 (2002)
[2] S.K. Das, J.A.S. Green, J.G. Kaufman, Light Metal Age 68, 42 (2010)

[3] S. Lü, S. Wu, C. Lin, P. An, Acta Metall. Sin. (Engl. Lett.) 27, 862 (2014)

[4] Y.X. Zhang, W.C. Liu, X.F. Liu, J. Mater. Sci. Technol. 32, 48 (2016)

[5] M.A. Moustafa, J. Mater. Process. Technol. 209, 605 (2009)

[6] T. Gao, Y.Y. Wu, C. Li, X.F. Liu, Mater. Lett. 10, 191 (2013)

[7] C.P. Li, X. Liu, J. Tian, Acta Metall. Sin. 25, 72 (1989)

[8] G. Gustafsson, T. Thorvaldsson, G.L. Dunlop, Metall. Mater. Trans. A 17, 45 (1986)

[9] X.F. Liu, X.F. Bian, Y.X. Liu, G.H. Zhang, J.J. Ma, Acta Metall. Sin. 33, 1062 (1997)

[10] H. Matsubara, N. Izawa, M. Nakanishi, J. Jpn. Ins. Light Met. 48, 93 (1998)

[11] N. El-Kaddah, A.D. Patel, T.T. Natarajan, JO M 47, 46 (1995)

[12] C. Li, Y.Y. Wu, H. Li, X.F. Liu, Acta Mater. 59, 1058 (2011) 